\title{
Influence of temperature and moisture on the mechanical properties of irradiated thermoplastics materials
}

\author{
Stoklasek Pavel $^{1}$ and Bednarik Martin ${ }^{1, *}$ \\ ${ }^{1}$ Tomas Bata University in Zlin, TGM 5555, 760 01, Zlin, Czech Republic
}

\begin{abstract}
This study deals with the effect of ionizing beta radiation on notch impact strength of polyamides filled with glass fiber under the influence of temperature and moisture. These properties were examined in dependence on the dosage of this ionizing beta radiation (non-irradiated samples and those irradiated by dosage 66 , and $132 \mathrm{kGy}$ were compared).
\end{abstract}

\section{Introduction}

The modification of polymer properties by irradiation is constantly evolving area. Ionic and ionizing radiation are the main types of radiation which are used for the polymer modification. Gamma radiation created from radioactive isotope $\mathrm{Co}-60$ (60Co) belongs to ionizing radiation as well as beta radiation (electron beam) and $\mathrm{X}$-ray radiation. All of these types significantly differ, however during these all process the energy transfer to atoms of irradiated material occurs [1-6].

As stated in previous investigations [6-16], it is possible to effectively change physical, mechanical and biological properties of irradiated material by ionizing radiation. These changes are probably caused by primary and secondary processes which are created due to interaction of ionizing radiation with polymer $[1,2,3]$.

$\begin{array}{ll}\text { Ionization } & \mathrm{P} \rightarrow \mathrm{P}^{+}+\mathrm{e}^{-} \\ \text {Excitation } & \mathrm{P} \rightarrow \mathrm{P}^{*} \\ \text { Thermal stabilization of electron } & \mathrm{e} \rightarrow \mathrm{e}_{\mathrm{th}}^{-} \\ \text {Neutralization } & \mathrm{P}^{+}+\mathrm{e}_{\mathrm{th}}{ }^{-} \rightarrow \mathrm{P}^{*} \\ \text { Free-radical generation } & \mathrm{P}^{*} \rightarrow \mathrm{R}_{1}{ }^{*}+\mathrm{R}_{2}{ }^{*} \\ & \rightarrow \mathrm{R}^{\cdot}+\mathrm{H}^{\cdot}\end{array}$

Fig. 1. Primary processes (P-polymer, R-radical) [1].

\begin{tabular}{|c|c|c|}
\hline Hydrogene abstraction & $\mathrm{R}^{\bullet}+\mathrm{P}$ & $\rightarrow \mathrm{RH}+\mathrm{P}^{\bullet}$ \\
\hline Double-bond addition & $\cdot \mathrm{RCH}=\mathrm{CH}_{2}$ & $\rightarrow \mathrm{RCH}_{2} \mathrm{CH}_{2} \cdot$ \\
\hline Crosslinking or branching & $\mathrm{R}_{\mathrm{m}} \cdot+\mathrm{R}_{\mathrm{n}} \cdot$ & $\rightarrow \mathrm{R}_{\mathrm{m}}-\mathrm{R}_{\mathrm{n}}$ \\
\hline Chain scission & $\rightarrow$ & $\mathrm{R}_{\mathrm{k}}{ }^{\cdot}+\mathrm{R}_{1}$ \\
\hline Oxidation & $\mathrm{R}^{\bullet}+\mathrm{O}_{2}$ & $\rightarrow \mathrm{ROO}^{\bullet}$ \\
\hline \multirow{3}{*}{ Grafting } & $\mathrm{ROO}^{\bullet}$ & $\rightarrow \quad-\mathrm{C}=\mathrm{O},-\mathrm{OH},-\mathrm{COOH}$ \\
\hline & $\mathrm{R}^{\bullet}+\mathrm{M}$ & $\rightarrow \mathrm{RM}^{\bullet}$ \\
\hline & $\mathrm{RM}^{\bullet}+\mathrm{nM}$ & $\rightarrow \mathrm{RM}_{\mathrm{n}+1^{*}}$ \\
\hline
\end{tabular}

Fig. 2. Secondary processes (M-monomer) [1].
Ionization, excitation and free radicals generation belong to primary interactions. Secondary reactions include crosslinking or branching, chain scission, oxidation and grafting, which follow after the free radical generation $[1,2,3]$. The primary and secondary processes are shown in the Figure 1 and 2 [1].

Various polymeric materials have various reactions on radiation, especially in case of crosslinking and chain scission (refer with: Table 1). Crosslinking and chain scission are two competitive processes, which always coexist during irradiation and the overall irradiation effect depends on which process predominate in given time (crosslinking or chain scission) [1-6].

Table 1. Classification of polymers according to their response to ionizing radiation [2].

\begin{tabular}{|c|c|}
\hline $\begin{array}{l}\text { Polymers predominantly } \\
\text { crosslinking }\end{array}$ & $\begin{array}{l}\text { Polymers } \\
\text { predominantly } \\
\text { degrading }\end{array}$ \\
\hline Polyethylene & Poly(tetrafluoroethylene) \\
\hline Polystyrene & Poly(vinyl fluoride) \\
\hline Polypropylene & $\begin{array}{l}\text { Poly(methyl } \\
\text { methacrylate) }\end{array}$ \\
\hline Polyamides & Polyoxymethylene \\
\hline Poly(vinyl chloride) & Poly(ethylene sulfide) \\
\hline Polyesters & Polyisobutylene \\
\hline Poly(vinyl methyl ether) & Polyacrylonitrile \\
\hline Poly(vinyl acetate) & Poly(propylene sulfide) \\
\hline
\end{tabular}

The crosslinking level can be adjusted by irradiation dosage and often by means of a crosslinking booster. The main difference between electron beta and photon gamma is in their different abilities of penetrating the irradiated material. Gamma rays have a high penetration capacity. The penetration capacity of electron rays depends on the energy of the accelerated electrons. Due to accelerated electron the required dose may be applied for seconds, whereas several hours are required on the gamma radiation plant. The electron accelerators operate 
on the principle of the Braun tube, whereby a hot cathode is heated in vacuum to such a degree that electrons are released [17-21].

This study deals with the influence of different doses of ionizing beta radiation on notch impact strength of polyamides filled with glass fiber under the influence of temperature and moisture and follows previous studies $[3,5,7,9,10]$, which described the change of mechanical properties of selected types thermoplastics.

The previous study $[3,5,7,9,10]$ proved the positive irradiation effect on mechanical of selected types polymers. Nevertheless, some findings are not explained yet, namely the change of dynamic properties during the application of beta radiation on material under thermal loading. Each new finding on the effect of radiation crosslinking on the properties of polymer materials may thus contribute to a better understanding of the issue and can extend the field of new applications.

\section{Experimental}

\subsection{Materials}

For this experiment two types polyamides were used. Both materials are filled with glass fibers and their commercial names are:

- Polyamide 66 GF 30 - V - PTS - CREAMID A3H7.2G 6*M0129A Schwarz

- Polyamide 7T GF 56 - V - DURAMID TH7 G12.0SZB*9207

The basic properties of used materials are shown in Table 2 and 3.

Table 2. Properties of PA 66 GF 30.

\begin{tabular}{|l|c|}
\hline \multicolumn{2}{|c|}{ PA 66 GF 30} \\
\hline \hline Density $\left[\mathrm{g} / \mathrm{cm}^{3}\right]$ & 1.37 \\
\hline Impact toughness $\left[\mathrm{kJ} / \mathrm{m}^{2}\right]$ & 8 \\
\hline Tensile modulus $[\mathrm{MPa}]$ & 10000 \\
\hline Bending strength $[\mathrm{MPa}]$ & 260 \\
\hline Softening temperature $\left[{ }^{\circ} \mathrm{C}\right]$ & 255 \\
\hline
\end{tabular}

The samples were made using the injection molding technology on the injection molding machine Arburg Allrounder $470 \mathrm{H} 1000-400$. The samples had the shape and dimensions according to the CSN EN ISO 179.
Processing conditions during the injection moulding were according to the recommendation of the procedures.

Test specimens were equipped with a notch type V (size $2 \mathrm{~mm})$.

Table 3. Properties of PA 7T GF 56.

\begin{tabular}{|l|c|}
\hline \multicolumn{2}{|c|}{ PA 7T GF 56 } \\
\hline \hline Density $\left[\mathrm{g} / \mathrm{cm}^{3}\right]$ & 1.63 \\
\hline Impact toughness $\left[\mathrm{kJ} / \mathrm{m}^{2}\right]$ & 25 \\
\hline Tensile modulus $[\mathrm{MPa}]$ & 19000 \\
\hline Bending strength $[\mathrm{MPa}]$ & 290 \\
\hline Softening temperature $\left[{ }^{\circ} \mathrm{C}\right]$ & 229 \\
\hline
\end{tabular}

All samples were irradiated with electron (beta) rays (electron energy $10 \mathrm{MeV}$, radiation doses: 66 and 132 $\mathrm{kGy}$ ) in the firm BGS Beta Gamma Service $\mathrm{GmbH} \&$ Co, Saal am Danau - Germany [7, 14, 15].

\subsection{Determination of crosslinked phase (gel) and mechanical characteristic}

For determination the crosslinked phase (gel) there was used a gel test. Test conditions were according to the CSN EN 579 [3].

For testing the mechanical properties there was used a dynamic test on the test machine Zwick HIT50P. Test conditions were according to the CSN EN ISO 179. The energy of the hammer was $50 \mathrm{~J}$ and test data was processed by Test Xpert II software.

After irradiation, the test specimens were exposed to the effects of temperature and moisture (168 hours at $75^{\circ} \mathrm{C}$ and $98 \%$ moisture).

\section{Results and discussion}

\subsection{The content of crosslinked phase}

As it is apparent from measurement results, the ionizing beta radiation significantly increases the content of crosslinked phase (refer with: Fig. 3). 


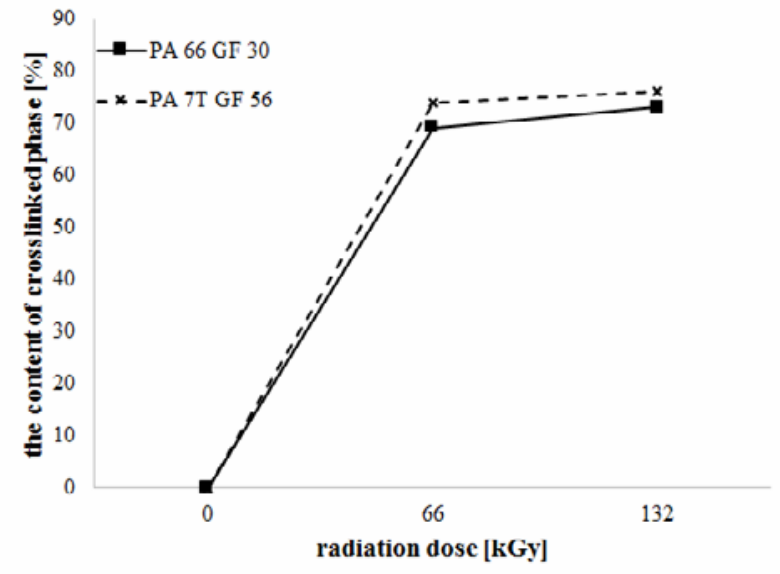

Fig. 3. Variation of content of crosslinked phase.

From this can be deduced that the higher amount of crosslinked phase (gel) the higher amount of structural net created mainly in the amorphous phase of PA 66 GF 30 and PA 7T GF 56 as a result of irradiation [1-3].

These changes have resulted in improvement of mechanical properties of tested materials.

\subsection{Notch impact strength - PA 66 GF 30}

Comparison of notch impact strength and maximum force (at $75{ }^{\circ} \mathrm{C}$ and $98 \%$ moisture) of PA $66 \mathrm{GF} 30$ before and after irradiation is given in the Figures 4 and 5 .

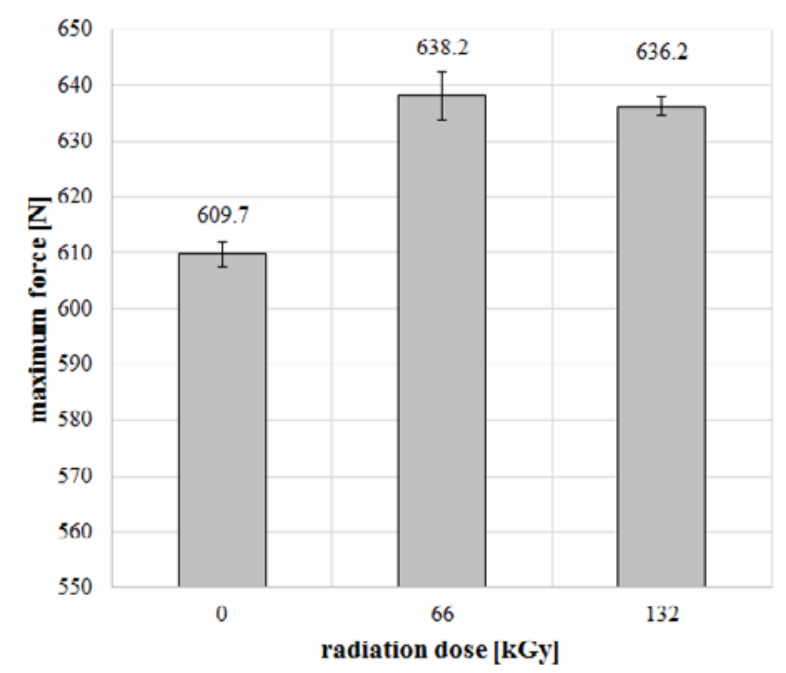

Fig. 4. Maximum force - PA 66 GF 30.

In the case of maximum force the highest increase was achieved at a dose of $66 \mathrm{kGy}$ and the lowest change of maximum force was measured at a dose of $132 \mathrm{kGy}$. In the case of irradiated with a dose of $66 \mathrm{kGy}$ the maximum force increased from 609.7 $\mathrm{N}$ (non-irradiated samples) to $638.2 \mathrm{~N}$ (dose of $66 \mathrm{kGy}$ ), which is a hike of approximately $5 \%$ (referring to: Fig. 4).

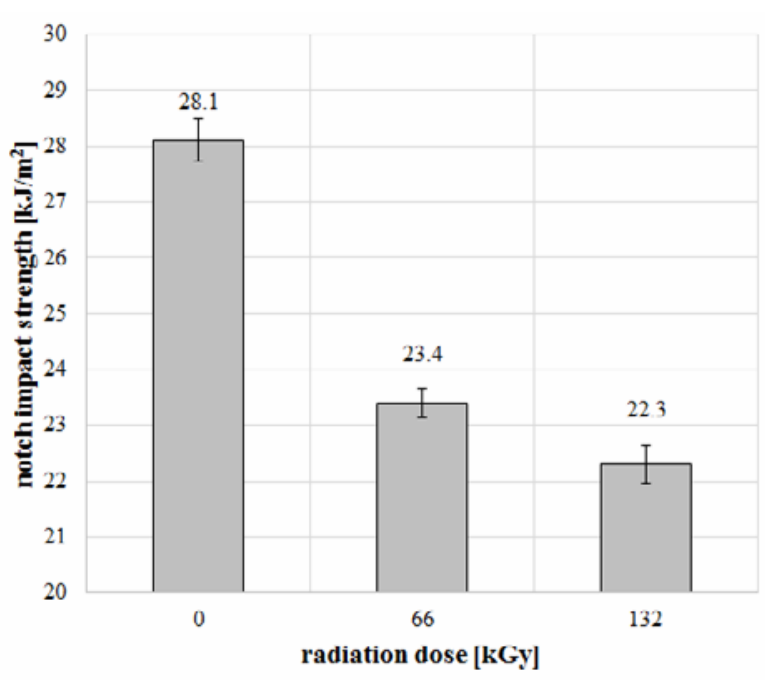

Fig. 5. Notch impact strength - PA 66 GF 30.

In the case of notch impact strength, the observed values decreased (due to irradiation). The highest decrease was achieved at a dose of $132 \mathrm{kGy}$. In the case of irradiated with a dose of $132 \mathrm{kGy}$ the notch impact strength decreased from $28.1 \mathrm{~kJ} / \mathrm{m}^{2}$ (non-irradiated samples) to $22.3 \mathrm{~kJ} / \mathrm{m}^{2}$ (dose of $132 \mathrm{kGy}$ ), which is a drop of approximately $20 \%$ (referring to: Fig. 5).

\subsection{Notch impact strength - PA 7T GF 56}

Comparison of notch impact strength and maximum force (at $75{ }^{\circ} \mathrm{C}$ and $98 \%$ moisture) of PA 7 T GF 56 before and after irradiation is given in the Figures 6 and 7.

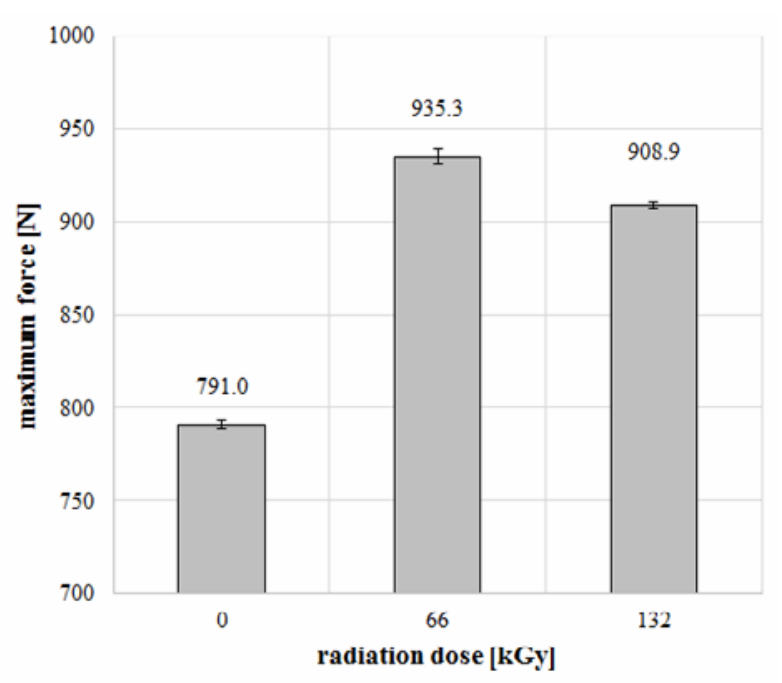

Fig. 6. Maximum force - PA 7T GF 56.

In the case of maximum force the highest increase was achieved at a dose of $66 \mathrm{kGy}$ and the lowest change of maximum force was measured at a dose of $132 \mathrm{kGy}$. In the case of irradiated with a dose of $66 \mathrm{kGy}$ the maximum force increased from $791.0 \mathrm{~N}$ (non-irradiated samples) to $935.3 \mathrm{~N}$ (dose of $66 \mathrm{kGy}$ ), which is a hike of approximately $20 \%$ (referring to: Fig. 6). 


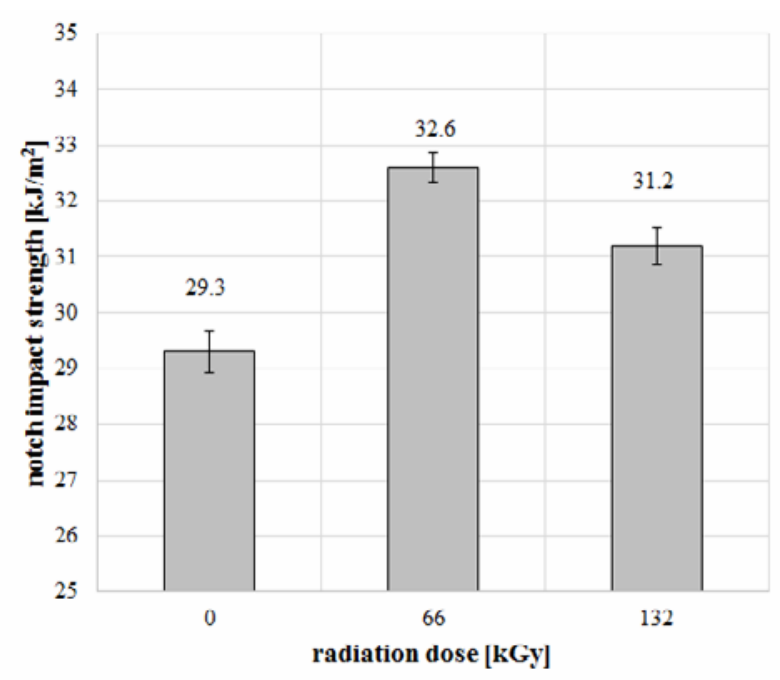

Fig. 7. Notch impact strength - PA 7T GF 56.

In the case of notch impact strength the highest increase was achieved at a dose of $66 \mathrm{kGy}$ and the lowest change of notch impact strength was measured at a dose of 132 $\mathrm{kGy}$. In the case of irradiated with a dose of $66 \mathrm{kGy}$ the notch impact strength increased from $29.3 \mathrm{~kJ} / \mathrm{m}^{2}$ (nonirradiated samples) to $32.6 \mathrm{~kJ} / \mathrm{m}^{2}$ (dose of $66 \mathrm{kGy}$ ), which is a hike of approximately $10 \%$ (referring to: Fig. 7).

\section{Conclusion}

This study deals with the influence of different doses of ionizing beta radiation on notch impact strength of polyamides filled with glass fiber under the influence of temperature and moisture. From the measurement results follows, that the ionizing beta radiation appears to be a very effective way to increase the mechanical properties. The consequence of irradiation is the creation of the covalent bonds among the macromolecular strings which are more flexible during thermal load than intermolecular forces $[2,3,7,14,15]$. These changes (together with the rise of content of crosslinked phase) have resulted in an significant improvement in mechanical properties of tested polyamides.

Changes due to irradiation were seen primarily in material with higher content of filler (PA 7T GF 56).

\section{Acknowledgments}

This paper is supported by the internal grant of TBU in Zlin No.IGA/FT/2017/010 funded from the resources of specific university research and by the Ministry of Education, Youth and Sports of the Czech Republic within the National Sustainability Programme project No. LO1303 (MSMT-7778/2014) and also by the European Regional Development Fund under the project CEBIA-Tech No. CZ.1.05/2.1.00/03.0089.

\section{References}

1. K. Makuuchi, S. Cheng, Radiation processing of polymer materials and its industrial applications, Wiley, Hoboken, N.J. (2012)

2. J.G. Drobny, Ionizing Radiation and Polymers: Principles, Technology and Applications, Elsevier, Oxford (2013)

3. M. Bednarik, A. Skrobak, V. Janostik, Key Eng. Materials (to be published)

4. Dj. Gheysari, A. Behjat, M. Haji-Saeid, European Polymer Journal 37, 8 (2001)

5. A. Mizera, M. Manas, D. Manas et al., Key Eng. Materials 662, 4 (2015)

6. S. Satapathy, S. Chattopadhyay, K.K. Chakrabarty et al., Journal of Applied Polymer Science 101, 12 (2006)

7. Z. Holik, M. Manas, M. Danek, J. Macourek, Chem. Listy 103, 4 (2009)

8. J. Navratil, M. Manas, M. Stanek, et al., Key Eng. Materials 662, 4 (2015)

9. M. Ovsik, D. Manas, M. Manas, et al., Key Eng. Materials 699, 6 (2016)

10. P. Stoklasek, A. Mizera, M. Manas, M. Bednarik, MM Science Journal 2016, 5 (2016)

11. M. Bednarik, D. Manas, M. Manas, et al., Defect and Diffusion Forum 368, 4 (2016)

12. J. Gehring, A. Zyball, Radiation Physics and Chemistry 46, 6 (1995)

13. J. Navratil, M. Manas, A. Mizera, et al., Radiation Physics and Chemistry 106, 5 (2015)

14. Z. Holik, M. Danek, M. Manas, et al., International Journal of Mechanics 5, 8 (2011)

15. M. Bednarik, D. Manas, M. Manas, et al., MATEC Web of Conferences 76 (2016)

16. D. Manas, M. Manas, A. Mizera, et al., Key Eng. Materials 662, 4 (2015)

17. J.G. Drobny, Radiation Technology for Polymers, CRC Press, Boca Raton (2003)

18. D. Manas, M. Manas, M. Stanek, T. Drga, Chem. Listy 101, 2 (2007)

19. D. Manas, M. Ovsik, M. Manas, M. Stanek, J. Javorik, P. Kratky, Key Eng. Materials 586, 4 (2014)

20. M. Manas, M. Stanek, D. Manas, M. Danek, Z. Holik, Chem. Listy 103, 5 (2009)

21. M. Ovsik, P. Kratky, D. Manas, M. Manas, M. Stanek, M. Bednarik, Key Eng. Materials 606, 4 (2014) 